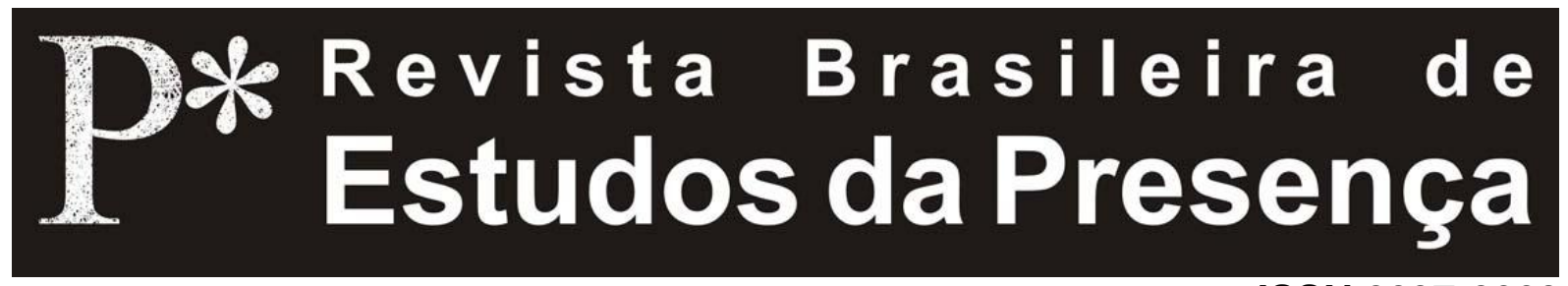

DOI - http://dx.doi.org/10.1590/2237-266021200

ISSN 2237-2660

\title{
Contadores de Histórias sobre Teatro e Educação
}

\author{
Vera Lúcia Bertoni dos Santos \\ Universidade Federal do Rio Grande do Sul - UFRGS
}

RESUMO - Contadores de Histórias sobre Teatro e Educação - $\mathrm{O}$ texto propõe-se a refletir sobre algumas experiências de ensino e aprendizagem referentes ao conhecimento nos campos do teatro e da educação protagonizadas por professores de teatro em formação acadêmica de nível superior. Nesse sentido, enfocam-se as relações que se estabelecem entre as narrativas desses sujeitos de acontecimentos significativos das suas próprias histórias de vida e o processo de construção de conhecimento que envolve a docência em teatro, à luz da perspectiva interacionista. $\mathrm{O}$ material empírico do qual se extraem os dados que ilustram o estudo é constituído por narrativas textuais orais e escritas elaboradas por esses sujeitos; e as análises desses dados mediante conceitos de autores como Piaget, Damásio e Freire permitem enfatizar o caráter processual, relacional e coletivo da aprendizagem do professor de teatro.

Palavras-chave: Teatro. Educação. Conhecimento. Experiência. Narrativa.

ABSTRACT - Storytellers about Theater and Education - The
text aims to reflect on some experiences of teaching and learning
that refers to the knowledge in the fields of theater and education,
starred by academic drama teachers in Education level. In this
signification, it is focused on the relationships established between
the narratives of these individuals and of this significative events of
their own story lives and the process of construction of knowledge
that involves the teaching in theater, in light of the interactionist
perspective. The empirical material from where is extracted the
data which illustrate this study is consisted by oral textuals

Vera Lúcia Bertoni dos Santos, Contadores de Histórias sobre Teatro e Educação

R.bras.est.pres., Porto Alegre, v.1, n.1, p. 189-213, jan./jun., 2011.

Disponível em http://www.seer.ufrgs.br/presenca 
narratives and writings elaborated by these individuals, and the analysis of this data through concepts of authors as Piaget, Damásio and Freire permitting emphasize the procedural nature, relational and collective learning of the drama teacher.

Keywords: Theater. Education. Knowledge. Experience. Narrative.

\section{RÉSUMÉ - Conteurs d'Histoires sur le Théâtre et l'Éducation}

- Le texte est une réfléxion sur quelques expériences d'enseignement et d'apprentissage concernant la connaissance dans les domaines du théâtre et de l'éducation vécues par des professeurs de théâtre en formation académique de niveau supérieur. Dans ce sens, sont abordées les relations qui s'établissent entre les récits de ces individus sur des événements significatifs de leurs propres histoires de vie et le processus de construction de la connaissance qui implique l'enseignement dans le théâtre, en ayant pour base la perspective interactionniste. Le matériel empirique dont sont prélevées les données qui illustrent cette étude est constitué par des récits textuels oraux et écrits élaborés par ces individus; et les analyses de ces données selon les concepts d'auteurs comme Piaget, Damásio et Freire permettent de mettre en relief le caractère processuel, relationnel et collectif de l'apprentissage du professeur de théâtre.

Mots-clés: Théâtre. Éducation. Connaissance. Expérience. Récit.

Neste texto apresenta-se um excerto de uma investigação mais ampla, situada no campo de estudos da Pedagogia do Teatro, que enfoca o processo de construção de conhecimento em teatro e em educação na perspectiva epistemológica interacionista.

$\mathrm{O}$ propósito central do trabalho investigativo discutido no texto é compreender o processo de formação do professor de teatro, buscando equilibrar o estudo da teoria construtivista e a análise de aspectos contextuais de propostas pedagógicas desenvolvidas na sala de aula de uma disciplina integrante do currículo do Curso de Licenciatura em Teatro. A proposta dessa disciplina é abarcar aspectos metodológicos do ensino do teatro mediante a teorização e a experimentação de diferentes formas de abordagem que objetivam a aprendizagem de conhecimento nesse campo e promovem a conceituação de múltiplos aspectos que envolvem esse processo.

O material empírico do qual se extraem os dados da investigação é resultante de ações coletivas de construção de conhecimento em teatro, e a sua análise desenvolve-se a partir de reflexões acerca das relações estabelecidas 
entre as narrativas dos professores em formação acadêmica de nível superior em relação às suas próprias experiências de vida referentes ao teatro e à educação, e o processo de apropriação de conhecimentos fundamentais à formação docente, à luz da perspectiva interacionista.

Ao longo do texto são apresentados fragmentos de depoimentos de cunho memorialista, referentes a histórias de vida dos licenciandos em teatro e aos seus modos de enunciação oral e escrita, considerados desencadeadores dos processos de interação entre os sujeitos da sala de aula e, portanto, primordiais ao estabelecimento da relação de ensino e aprendizagem. Tais depoimentos são analisados como pontos de partida, ou metas de chegada, do processo de interação entre os professores em formação, sujeitos da investigação, e o conhecimento, na medida em que estes, apropriados de acontecimentos significativos das suas histórias de vida em relação ao teatro e à educação, tendem à elaboração de visões mais amplas das suas próprias experiências, passando a compreendê-las no sentido sócio-histórico e crítico.

\section{Pontos de Partida, ou Metas de Chegada}

No livro A História do Cerco de Lisboa, o escritor português José Saramago apresenta uma visão peculiar acerca da amplitude dos domínios do fazer literário, que se expressa, oportunamente, através de um dos sábios dizeres do personagem Raimundo Silva, um revisor de literatura com pendores à filosofia, em cuja discreta opinião, "[...] tudo quanto não for vida, é literatura" (Saramago, 1989, p. 15).

Para argumentar em favor da sua teoria, Silva não economiza nas comparações, referindo-se "sem querer ofender", à história, à música (que, segundo ele, oscila entre o "livrar-se" da palavra ou a ela, por obediência, regressar) e mesmo a pintura, como formas de contar, esta última, "com pincéis", o vivido, o sentido (Saramago, 1989, p. 15).

Simpatizante das ideias de Silva no que tange ao texto literário como produção da subjetividade, este trabalho propõe-se a relatar fragmentos de histórias contadas por professores de teatro em formação, sem se preocupar propriamente com a objetividade ou a 
veracidade dos fatos vividos (posto que estes já fazem parte da história, e lá estão, por assim dizer), mas sim com a compreensão das suas significações no sentido da reflexão, ou seja, com as tomadas de consciência que possibilitam a apropriação das transformações evidenciadas nas andanças de seus contadores pelos caminhos do teatro e da educação.

O epistemólogo Jean Piaget (1983) enfatiza a relação de paralelismo entre o inconsciente afetivo, do qual se ocupa a psicanálise, e o inconsciente cognitivo, concernente ao estudo da inteligência, da representação e das funções da cognição, e caracteriza o aspecto afetivo das condutas por suas "composições energéticas" e o aspecto cognitivo, por suas características estruturais (Piaget, 1983, p. 226-234).

Sob esse prisma, é possível considerar que a afetividade traduz-se pelos sentimentos do indivíduo independentemente da consciência deste em relação aos mecanismos responsáveis pela evocação (representação) daqueles, enquanto que o aspecto da cognição diz respeito ao conjunto de estruturas e de funcionamentos do pensamento (conteúdo e forma), quer nos estágios mais elementares do desenvolvimento do indivíduo, correspondentes a fontes (quase absolutamente) inconscientes, tais como a atividade reflexa, quer nos níveis superiores, que apresentam consciência (sempre relativa) dos seus processos funcionais e estruturais, como, por exemplo, o pensamento científico (e não faltam exemplos de tomadas de consciência a edificar ou pôr termo a paradigmas na história da ciência).

Nesse mesmo sentido pendem as reflexões do neurologista António Damásio (2000), que se questiona acerca das dificuldades que se impõem ao saber epistemológico. "O que poderia ser mais difícil de conhecer do que conhecer o modo como conhecemos?", indaga $o$ autor. Embora Damásio insista em não considerar a consciência como o ápice da evolução biológica, ele define a consciência como a "transição crítica" da "inocência e da ignorância para o conhecimento e o autointeresse". E, nesse sentido, destaca o papel crucial da consciência na evolução humana no que se refere a determinadas criações, tais 
como a "consciência moral", a "religião", a "organização social e política", as "artes", as "ciências" e a "tecnologia", que seriam impossíveis sem a sua intervenção (Damásio, 2000, p. 18). Nessa concepção:

A consciência, de fato, é a chave para que se coloque sob escrutínio uma vida, seja isso bom ou mau; é o bilhete de ingresso, nossa iniciação em saber tudo sobre fome, sede, sexo, lágrimas, riso, prazer, intuição, o fluxo de imagens que denominamos pensamento, os sentimentos, as palavras, as histórias, as crenças, a música, a poesia, a felicidade e o êxtase. Em seu nível mais simples e mais elementar, a consciência permite-nos reconhecer um impulso irresistível para permanecer vivos e cultivar o interesse pelo self. Em seu nível mais complexo e elaborado, a consciência ajudanos a cultivar um interesse por outras pessoas e aperfeiçoar a arte de viver (Damásio, 2000, p. 20).

Damásio destaca o preponderante papel da consciência na experiência humana e, propondo-se a enfrentar os obstáculos à compreensão desse processo, examina diferentes mecanismos a ele correlacionados. Desse modo, ao investigar o tema da consciência na perspectiva da neurologia, ele revela a conexão existente entre a consciência (padrão mental unificador do objeto e do self) de si e a emoção, compreendendo o corpo como "[...] representação dinâmica de uma entidade com variações de estados possíveis" (Damásio, 2000, p. 187), que, a cada momento, o cérebro tem à disposição. Nesse sentido, a base para a consciência central, ou, conforme Damásio (2000, p. 222), para a constituição do sentido do "self central transitório", "[...] surge na 're-presentação' do proto-self inconsciente no processo de ser modificado dentro de um relato que estabelece a causa da modificação".

Segundo o autor, a criação desse relato (história) tem como resultado primeiro a consciência do próprio ato de conhecer, ou seja, um sentimento de si através do qual o indivíduo percebe-se, momentaneamente, protagonista da sua narrativa, o que não significa necessariamente a percepção dos detalhes que a constituíram ou da sua totalidade, mas a descoberta (conhecimento) da própria existência, mediante a categorização e o relacionamento 
de fatos passíveis de registro na memória, sejam eles referentes ao passado ou a um futuro que se antevê.

Esse processo relaciona-se à constituição, por ampliação ou remodelação, da chamada memória autobiográfica do indivíduo, que congrega, no decorrer da experiência de vida deste, registros a dizer as suas qualidades físicas e os seus comportamentos individuais, e a predizer (projetar) modos de ser e de agir na sua experiência futura. Tais registros tendem, na medida da necessidade e da capacidade individual de reconstituição ou explicitação por meio de imagens, a originar o self autobiográfico que, por sua vez, não apenas reflete aspectos mais ou menos variáveis da biografia memorizada pelo indivíduo, mas se baseia num conceito (no sentido cognitivo do termo), ou seja, constitui uma totalidade de memórias implícitas, tipificadas tanto pela experiência passada quanto pelas projeções de que o indivíduo é capaz e que, num dado momento da experiência atual, são ativadas (explicitadas), ocasionando modificações parciais, numa relação dinâmica e retroativa no sentido da progressiva conscientização.

Feita essa introdução notadamente teórica (posta aqui na intenção de salvaguardar este texto do aspecto aparentemente prático que ele assume daqui em diante), alinham-se a seguir alguns fragmentos de depoimentos alusivos a experiências relacionadas ao teatro e à educação, protagonizadas por estudantes de Licenciatura em Teatro. Através da análise dessas narrativas busca-se explicar condutas e processos relativamente conscientizados por esses sujeitos, considerados os problemas afetivos e os limites estruturais que se interpõe à compreensão dos fatos registrados e à ultrapassagem da experiência no sentido da sua conceituação.

\section{Contar}

Nas aulas de Metodologia do Ensino de Teatro, a mobilização da atenção dos licenciandos costuma ter início através do exercício de contar a própria história, ou seja, uma prática pedagógica designada por Memorial, que ocorre a partir do primeiro dia de aula da disciplina, mediante a proposição da narrativa oral de experiências 
pessoais dos estudantes em relação ao teatro e à educação.

A proposta do Memorial desenrola-se, ao longo do semestre letivo, num processo de produção textual que tem por objetivo o detalhamento e a reflexão dessas experiências noutro plano de formalização, ou seja, o plano da escrita. Os textos escritos passam por remodelações por meio de revisões, avaliações individuais e exposições ao grupo, até chegarem à sua forma final, refletindo-se na avaliação global da disciplina.

Além de significar a compreensão das trajetórias individuais dos estudantes, esse expediente metodológico mostra-se especialmente valioso para a concepção dos Trabalhos de Conclusão de Curso (TCCs) - instância de culminância e convergência dos graduandos. Entretanto, é justamente por constituir possibilidade de organização e aprofundamento das reflexões e tomadas de consciência dos fatos que permeiam as histórias de vida desses estudantes, que a prática do Memorial parece revelar o seu maior valor, porquanto permite aos grupos, em especial aos alunos na fase inicial da formação universitária, transformar os seus conhecimentos prévios e a sua maneira de compreendê-los, na medida em que se tornam capazes de compartilhar experiências e identificar interesses e pontos de vista, comuns ou controversos, sobre determinados temas, sobretudo aqueles de discussão recorrente nos âmbitos do teatro e da educação.

As narrativas ${ }^{1}$ desses sujeitos concernem tanto às aprendizagens correspondentes aos processos desenvolvidos no espaço acadêmico (considerados os seus diferentes níveis de sistematização), como às procedentes de experiências protagonizadas fora desse ambiente, isto é, abrangem os mais variados espaços e tempos da vida dos sujeitos.

Ou seja, nas conversas iniciais desenvolvidas na sala de aula observa-se, de modo geral, que os depoimentos tendem a enfocar fatos isolados e a ater-se a conteúdos mais pitorescos das histórias de vida dos licenciandos, evidenciando a heterogeneidade dos seus contextos, mas não manifestam preocupação em atribuir um sentido mais global à experiência relacionada ao 
teatro e à educação e, tampouco, revelam a compreensão do seu caráter processual e do aspecto relacional dos fatos que os compõem.

A estudante Raquel, por exemplo, numa maneira direta e empolgada de narrar os fatos vividos no ambiente familiar e no espaço escolar, destaca a importância do incentivo às suas apresentações teatrais, desde a infância, e faz menção à sua escolha pelo Curso de Magistério, no Ensino Médio, que a levou a lecionar numa escola de Educação Infantil, à sua busca por frequentar oficinas de teatro e ao ingresso no curso de Licenciatura em Teatro. E o licenciando Pedro, por sua vez, descreve experiências teatrais vivenciadas nas três escolas em que estudou no decorrer da Educação Básica e relata uma experiência de sucesso numa representação teatral realizada nos seus tempos de quartel, segundo ele decisiva na sua relação com o teatro e no despertar do seu interesse pela área da atuação. Ele menciona, também, algumas experiências artísticas profissionais junto a grupos de teatro, como autor de contos e de peças teatrais e como professor da área vinculado ao ensino informal ou a instituições e sindicatos.

Em oposição a esses depoimentos considerados mais descritivos, a narrativa de Bia busca arrolar as experiências mais significativas da sua iniciação nas artes de uma maneira mais reflexiva, fazendo menção aos jogos da infância, realizados em casa ou na rua, às brincadeiras de faz de conta com os irmãos mais novos, às atividades plásticas (desenhos, recortes) da pré-escola, aos jogos aprendidos na disciplina de Educação Física e às coreografias montadas no curso de Ginástica Rítmica, ambos frequentados nos anos iniciais da sua escolarização, período marcado positivamente pela sua participação em uma peça de teatro. Ela descreve também, com muita propriedade, à sua iniciação em dança, perpassada desde as experiências mais remotas da infância, vivida na sua cidade natal, até às práticas relacionadas a aprendizagens mais formais, que culminaram com a sua vinda para a Capital, motivada pela necessidade premente de aprofundar a dança como meio de expressão. Além disso, destaca o interesse pelo teatro, segundo ela um meio de expressão, que se tornou 
uma paixão; e enfatiza a experiência recente de trabalhar como professora de Expressão Corporal numa escola de Educação Infantil, assim como o crescimento pessoal possibilitado pelo trabalho artístico junto a grupos e diretores de teatro de expressão na cidade. Hoje, busco uma autonomia artística, diz ela, na finalização do seu articulado relato.

A narrativa de Bia parece constituir uma exceção dentre os depoimentos iniciais, pois indica, já nos primeiros momentos de interação com a disciplina, e em oposição à maneira descontextualizada e segmentada da narrativa da maior parte dos seus colegas, uma compreensão mais totalizadora da experiência, constatada pelos aspectos relacional e analítico dos fatos que compõem a sua própria história.

De modo geral, observa-se que a possibilidade de formalização das trajetórias desses licenciandos, seja por meio da fala ou da linguagem escrita, e as tomadas de consciência que ela tende a acarretar, correspondem a avanços significativos nos processos individuais de reflexão e na interação desses sujeitos entre si e com os conteúdos da disciplina.

As experiências lúdicas da infância são mencionadas em todos os Memoriais, e descritas como fundamentais à interação dos participantes da pesquisa com as formas dramáticas e teatrais. Os fragmentos a seguir exemplificam esse aspecto:

- Sempre brinquei muito: de escolinha, dando aula para as minhas bonecas, de casa na árvore ou nave espacial, de casinha e cabaninha, de gerente de banco e de escritório. [...] Incentivada pelo meu irmão, gostava de gravar entrevistas e reproduzir programas infantis [Raquel].

- Eu gostava muito de brincar de faz de conta. [...] No princípio brincava sozinha, depois, com o passar do tempo, criava grandes brincadeiras de faz de conta com a participação de primos e vizinhos. Era muito divertido [Maria].

- A minha rua ainda era de chão batido e tinha muitas construções pra gente brincar. Mas eu me lembro [...] das brincadeiras no sítio dos meus avós. Eu e o meu primo [...] adorávamos ir para lá, fazer piquenique, subir na figueira, 
chamar a gurizada para brincar de pegar, de esconder, de jogar futebol, vôlei, taco [Bela].

- Minha infância foi repleta de brincadeiras na rua e nos campos que permitiam jogos de futebol, taco, carrinho de lata, roletes, bolinhas de gude, pandorgas [...]. Mais tarde vêm as brincadeiras em grupos, esconde-esconde, polícialadrão, paralítico [Pedro].

- Nesse tempo, brincar, fazer piquenique [...], assim como dançar ao som do rádio era maravilhoso. Além das guerras de carrapicho e dos jogos infantis [...] o Passa passará, o Tá pronto seu lobo eram os que mais me encantavam [Bia].

As ideias nascentes acerca do caráter processual e interacionista da atividade lúdica da criança, expressas de diferentes maneiras nos Memoriais, mas nem por isso compreendidas como totalidade, possibilitaram que, nas propostas de sala de aula da disciplina, se enfatizassem alguns princípios fundamentais à tomada de consciência das relações entre $\mathrm{o}$ teatro $\mathrm{e}$ a construção de conhecimento. Assim, foi possível potencializar o interesse dos futuros professores pela constituição de uma teoria capaz de compreender a tendência evolutiva da brincadeira infantil no sentido dos jogos de regra e da formação do grupo de jogo e, dessa forma, abarcar a complexidade conceitual desse processo.

Outro aspecto que se destaca positivamente na abordagem das histórias de vida dos sujeitos refere-se às suas primeiras oportunidades de apreciação estética, haja vista a pluralidade e os caracteres social e cultural dos eventos assimilados a elas nos seus depoimentos.

Pedro faz referência ao despertar do seu gosto pela música, assimilando-o a experiências precoces do convívio familiar. Ele lembra também da sua curiosidade de menino pelas encenações cantadas, alusivas a celebrações e festividades religiosas da sua cidade, e da função dos seus familiares em torno dos preparativos das alegorias desses eventos. Menciona também o seu fascínio pelos causos contados por um tio nas rodas de chimarrão que reuniam a vizinhança nas noites de inverno: 
À noite em casa gostava de ouvir o pai, uns tios e os amigos deles tocar músicas do terno de reis, que possuíam toda uma encenação através das letras e da forma como chegavam nas casas e saíam. Havia muitos ensaios quando chegava a época de fim de ano. E eu ficava lá no cantinho atrás dos sofás só observando toda aquela movimentação; [...] um tio da minha mãe [...] começava a contar histórias de caçadas e pescarias que desembocavam em histórias, lendas e assombrações.

Bia, por sua vez, recorda-se das cerimônias religiosas frequentadas na companhia da mãe, do seu envolvimento com os irmãos em torno das vestimentas para as festividades de Carnaval e a sua primeira ida ao teatro:

[...] numa missa eu fugi do banco da igreja e fui dançar no altar, roubando a atenção dos fiéis; lembro-me dos primeiros carnavais [...] nossa mãe mandou fazer uma frente única poá [forma abrasileirada petit pois] e nosso pai deunos máscaras de papel. Lembro-me como num sonho de ter ido ao CTG [Centro de Tradições Gaúchas] assistir uma peça de teatro: era a história de um bando de crianças e tinha um menino muito alto de bermuda verde e camisa listrada [...] o cenário era um pátio onde tinha um varal de roupas.

Além do estreitamento das relações de grupo que essas histórias ocasionam no decorrer do semestre letivo, constata-se, no desenrolar das propostas pedagógicas, a maleabilidade desse tipo de visão relativa à experiência estética e à riqueza de possibilidades de ampliação suscitadas nos fazeres (ação e reflexão) da sala de aula.

No encaminhamento das discussões é possível conhecer o ponto de vista dos alunos, o que permite auxiliá-los a compreender, por meio da reflexão acerca da sua própria experiência, que a gênese do gosto pela arte e pela beleza e a experiência estética de qualidade não se processam atreladas a padrões e, tampouco, se limitam a regras exteriores, pois se compreendem genuinamente vinculadas ao desenvolvimento da inteligência dos sujeitos e às manifestações culturais da sua comunidade.

Essas percepções da teatralidade presente no cotidiano, e sua assimilação às experiências da infância, significam a base das concepções de teatro desses futuros

Vera Lúcia Bertoni dos Santos, Contadores de Histórias sobre Teatro e Educação

R.bras.est.pres., Porto Alegre, v.1, n.1, p. 189-213, jan./jun., 2011.

Disponível em http://www.seer.ufrgs.br/presenca 
professores, que, na medida do aprofundamento interdisciplinar da teoria e das práticas cênicas, tendem a compreender princípios inerentes ao ato teatral e suas relações com o ensino do teatro no meio escolar.

Ryngaert (1977) refere-se à necessidade de se procurar desenvolver formas dramáticas contemporâneas no ambiente escolar, buscando "inventar", por meio das mais inusitadas propostas, um "[...] teatro inscrito na vida cotidiana". Nesse tipo de manifestação, segundo o autor, "[...] tudo se torna sinal, desde que a imaginação se apodere do objeto extraído do nosso mundo" (Ryngaert, 1977, p. 66).

A narrativa de Lúcia evidencia uma visão própria de teatro, construída correlativamente à sua prática como atriz ligada a um grupo que pesquisa as diferentes formas de teatro de rua e ao seu aprofundamento nas teorias do jogo e do espetáculo contemporâneo:

[...] as "brincadeiras encenadas" da infância passaram a integrar a esfera profissional. O teatro de rua foi um divisor de águas na minha experiência, já que, parafraseando Artaud, a minha ideia "petrificada" de teatro desmanchou-se como papel na chuva, pois na rua não existe a divisão rígida entre palco plateia, nem um cenário ou um texto pronto e fechado; existem sim ator e público em sintonia, muitas vezes, construindo juntos a história, um enorme fluxo de pessoas assistindo ou passando [...], o que torna constante o desafio de prender a atenção de quem está assistindo.

Outro aspecto propulsor da discussão interdisciplinar do teatro e da educação é a experiência escolar. O ingresso dos sujeitos na escola (salvo um honroso caso que se refere ao ensino de nível pré-escolar e outro que menciona a liberdade das aulas de educação física, quando ocorridas no pátio) caracteriza-se em contraposição, ou, em parênteses, à atividade lúdica desenvolvida nos quintais, nas ruas, nos campos e cercanias da casa da infância, conforme ilustram estes fragmentos dos Memoriais de Pedro e Bela:

- Eu tinha todo um universo que acreditava completo, me dava por satisfeito, mas então chegou a época de ir para a escola. Foi uma barra no início, cheguei a ficar de recuperação aquele ano [...]. Aos poucos, meus irmãos

Vera Lúcia Bertoni dos Santos, Contadores de Histórias sobre Teatro e Educação

R.bras.est.pres., Porto Alegre, v.1, n.1, p. 189-213, jan./jun., 2011. 
foram entrando também no mesmo colégio e o ambiente foi ficando mais familiar [Pedro].

- Foi uma infância moleca [...] eu não parava em escola nenhuma [Bela].

A despeito disso, a maior parte dos depoimentos parece creditar a iniciação à experiência teatral formalizada à interação com o ambiente escolar. Os fragmentos a seguir expressam este aspecto:

- Foi lá [na escola] que tive a minha primeira experiência com o teatro, ou o chamado "teatrinho" [...] aquelas famosas peças que as professoras fazem nas datas comemorativas [Maria].

- Na primeira série [...] eu tive a minha primeira experiência com a encenação de um texto dramático [...], formando assim uma noção inicial de teatro, o que mais tarde descobri ser apenas um tipo de encenação e não um modelo universal [Lúcia].

- Foi lá [na escola] que eu conheci o teatro [Bela].

- Em [data], finalmente entrei para a escola, estava ansiosa. Lembro-me que no final do ano tivemos a apresentação da pré-escola [Raquel].

Entretanto, as experiências nesse sentido parecem refletir atividades regulares de diversas disciplinas do currículo, eventos do calendário da escola e mesmo os fortuitos momentos de recreio. Ou seja, conforme se pode constatar nos fragmentos de Memoriais que se seguem, não há qualquer menção à abordagem das formas dramáticas vinculadas, especificamente, ao ensino do teatro:

- A escola [...] era de freiras [orientação religiosa]. Desde a primeira série havia o costume de se fazer encenações sobre trechos da Bíblia [...] sempre com direito a figurino, maquiagem e efeitos especiais. $\mathrm{Na}$ aula de Língua Portuguesa tínhamos que escolher um livro e encenar sua história [Maria].

- Me responsabilizei pela montagem de "Romeu e Julieta" para a aula de história [...] sem noção alguma ou professor que pudesse nos auxiliar [Luna].

Vera Lúcia Bertoni dos Santos, Contadores de Histórias sobre Teatro e Educação

R.bras.est.pres., Porto Alegre, v.1, n.1, p. 189-213, jan./jun., 2011. 
- Participei da primeira apresentação teatral numa biblioteca [Pedro].

- Outra lembrança significativa eram as peças organizadas para receber o autor de um livro trabalhado [...], projeto denominado "O Autor vai à Escola" [Raquel].

- A minha peça de estreia foi no dia das mães, fiz o papel principal [Maria].

- Ao longo dos quatro anos do ginásio realizamos espetáculos de teatro que saíram da sala de aula para o pátio da escola como atração de datas comemorativas [Bia].

- Na hora do recreio dançávamos para todos verem [...] eu ficava organizando o público ao redor das apresentações [...]. Tínhamos um espaço proporcionado pelas professoras para mostrar um pouco do que gostávamos de fazer [Raquel].

Nesse sentido, mesmo as menções a atividades mais genéricas, ligadas à disciplina de Educação Artística, citada em alguns depoimentos, referem-se a professores sem formação na área de teatro, indicando a abordagem polivalente, como descrevem Bia e Lúcia:

- Pedimos para a professora de Educação Artística para fazer teatro [...] desenhamos o cenário no quadro negro, providenciamos roupas no acervo familiar e apresentamos para os colegas [Bia].

- A professora, que também lecionava Ensino Religioso, não possuía a formação necessária para nos auxiliar nas atividades teatrais, já que a sua formação era em Artes Plásticas, sendo assim, a nossa história não pôde evoluir, tornando-se chata e repetitiva [...] não havia desafio ou inovação nas apresentações. Essa cultura do professor de Educação Artística polivalente deveria ser derrubada pela regulamentação da LDB de 1996, que determina que os professores devem ter uma formação específica na sua área; mas nas escolas, infelizmente, a prática da polivalência ainda é corrente [...] ainda hoje o "teatro" é confundido com algo que engloba tudo o que possa ser apresentado, não importando a qualidade [...] como mero cartão de visitas, ou substituto de trabalhos [Lúcia]. 
Relatos como esses abrem caminho para a discussão sobre as questões conceituais e metodológicas do ensino de teatro na educação escolar e permitem que se pontuem aspectos importantes da teoria, tornados necessários pelos desequilíbrios e contradições surgidos na interação do grupo com as suas próprias experiências.

\section{Contar-se}

A sistematização dos Memoriais, bem como as muitas ações e coordenações desenvolvidas na medida da interação dos integrantes dos grupos pesquisados com os fatos marcantes das suas histórias de vida, possibilitam significativas alterações no modo de pensar desses sujeitos em relação ao seu processo de apropriação dos conteúdos abordados em sala de aula. É o que se pode verificar na narrativa de Lúcia, que parece refletir o caráter autobiográfico e autorreferenciável do conhecimento:

Ao entrar na quarta série, fui estudar num colégio [orientação religiosa] onde comecei a participar do que Ryngaert classifica como "teatro como meio", ou seja, as atividades teatrais em sala de aula utilizadas como meio para facilitar o aprendizado de outras disciplinas. Eu fazia parte de um grupo de alunos que, não importando a disciplina ou o assunto desenvolvido em aula, apresentava o trabalho na forma de teatro [...] chegamos a elaborar até uma história fixa em que enxertávamos os temas propostos pelos professores [...]. Nossas brincadeiras acabaram influenciadas pela ideia usual de teatro, Ryngaert escreveu acerca dessa influência [e cita as palavras do autor]: “a dramatização espontânea efetua-se, mesmo nas crianças mais novas, em função de modelos culturais compreendidos na palavra genérica 'teatro', saco onde cabe tudo, e está na origem de muitas incompreensões".

A partir de situações da sua vida escolar, a futura professora de teatro teoriza sobre a prática teatral como um recurso didático à abordagem de outras disciplinas do currículo e posiciona-se criticamente frente às lacunas da sua formação básica. Nesse sentido, ela faz menção a uma situação decorrente da falta de formação adequada dos professores ao encaminhamento do trabalho pedagógico, trazida em seguimento à descrição das 
peripécias do grupo de teatro formado por ela e seus colegas de quarta série do Ensino Fundamental:

[...] com o argumento de "formação de panelinha", a professora de educação artística dissolveu o grupo, colocando cada um de nós em um grupo diferente. Acostumada ao ritmo de trabalho dos meus colegas mais próximos, não consegui, e também não quis, me adaptar. Assim sendo, tirei a minha primeira nota vermelha [...] no boletim [...] uma nota cinco na minha matéria preferida.

Nas discussões de sala de aula motivadas pela leitura desse Memorial, a atitude autoritária da professora frente à intensa atividade do grupo de alunos foi analisada como um indício da precariedade do seu conhecimento no que tange ao desenrolar das descobertas das crianças no terreno da dramatização e às possíveis relações dessas formas com os primórdios da elaboração teatral; e o descaso para com a atividade das crianças, bem como a arbitrariedade da ação docente na adoção de medidas de punição pela via da avaliação negativa (a tão temida nota vermelha) foram identificados como consequências da dificuldade de compreensão e das inadequações do seu próprio autoritarismo.

O debate acerca desses e outros aspectos fundamentais à abordagem do teatro no meio escolar é ensejado em diversos momentos da interação dos sujeitos com a sua história, sendo desenvolvido na interdisciplinaridade das teorias de teatro e de aprendizagem, significando reflexões sobre o sentido ético e o caráter social do ato de conhecimento.

O texto a seguir, habilmente construído por Lúcia, mostra um modo exemplar de compreender a construção do conhecimento teatral:

O trabalho de grupo, a cooperação e o comum acordo são desenvolvidos nesse tipo de atividade, pois propõe um problema a ser solucionado e só começa a acontecer quando todos os seus participantes entram num consenso, ou, quando começam a se escutar, a respeitar opiniões uns dos outros, mesmo quando essas discordam das suas.

Observa-se que o fazer pedagógico refletido possibilita a esta jovem futura professora a compreensão

Vera Lúcia Bertoni dos Santos, Contadores de Histórias sobre Teatro e Educação

R.bras.est.pres., Porto Alegre, v.1, n.1, p. 189-213, jan./jun., 2011.

Disponível em http://www.seer.ufrgs.br/presenca 
de que a aprendizagem do teatro desenvolve-se na experiência de grupo e, como tal, não pode prescindir da atitude cooperativa e do consentimento de todos os participantes da relação educativa.

A despeito da carência de orientação específica ao desenvolvimento da atividade lúdica de caráter dramático no ambiente escolar, evidenciada na maior parte dos Memoriais e das conversas de sala de aula, os sujeitos mostram-se unânimes em reconhecer a importância do convívio com os colegas de escola na descoberta das primeiras formas de expressão e comunicação teatrais e na sua inserção social.

Nos fragmentos a seguir, os narradores relacionam a iniciativa das buscas de caminhos próprios para as primeiras investidas no sentido da aprendizagem formal do teatro à possibilidade de troca, de experimentação coletiva e de convívio nos grupos constituídos no ambiente escolar:

- Eu e minhas amigas nos reuníamos, revirávamos o guarda-roupas, nos maquiávamos [...] falávamos ao microfone ou criávamos alguma peça [Raquel].

- [...] eu tomava conta de tudo: distribuía os papéis, "dirigia" as cenas, inventava acessórios cênicos [...]. Foi uma época muito feliz da minha vida escolar. Eu tinha muitos amigos e cada vez fazia mais [Maria].

- [...] tocar músicas, leitura de muitos livros, grupos de estudo [...] minha participação foi maior em todas as atividades sociais estudantis [Pedro].

- [...] a nossa turma passou a ser referência para outros que se interessassem por teatro. Eu havia gostado muito daquilo, procurei cursos de teatro [Luna].

- [referindo-se a um curso extracurricular] a turma era muito legal, naquele ano a minha vida começava a mudar, comecei a trilhar um caminho único, um caminho sem volta, o caminho do teatro [Bela].

- Das adaptações de contos de fadas para adaptações dos quadros de humor da TV, preferência dos meninos, que no trajeto foram aderindo ao teatro [relata diversos "fazeres" em relação ao teatro e à dança]. E minha paixão cresceu, nada era mais importante [...] queria aprender mais [Bia].

Vera Lúcia Bertoni dos Santos, Contadores de Histórias sobre Teatro e Educação

R.bras.est.pres., Porto Alegre, v.1, n.1, p. 189-213, jan./jun., 2011.

Disponível em http://www.seer.ufrgs.br/presenca 
A incursão ao teatro profissional também suscita importantes depoimentos nos Memoriais. De modo geral, os alunos referem-se à possibilidade de participação em cursos e oficinas ministrados por artistas e técnicos atuantes nesse meio, conforme mostram os depoimentos a seguir:

- Depois de dois anos morando em [nome da cidade da sua adolescência] fiquei sabendo de uma oficina de teatro que acontecia na Prefeitura, sempre aos domingos à tarde. Fui conferir e em seguida já fazia parte do "Grupo Teatral [nome]" Em [data], [nome de um profissional da área do teatro] fora convidado para ministrar uma oficina, com ele aprendemos algumas técnicas circenses [...] empregadas em algumas esquetes apresentadas. A partir dali começamos a ensaiar um espetáculo infantil [...] chegou a hora de encarar o vestibular. Tinha uma certeza: quero fazer teatro! [Raquel].

- Um colega da minha irmã chegou em casa com um recorte de jornal indicando um curso no Teatro de Câmara com [nome de um profissional reconhecido no meio artístico local], mamãe não tinha como pagar, mas falou com minha tia e, juntas, perguntaram se eu queria isto de aniversário. Consegui, assim, fazer o meu primeiro curso de teatro [Luna].

Pedro, Bela e Bia, veteranos na atividade teatral profissional, em relação à maior parte dos colegas, ressaltam a formação das parcerias da adolescência como instituidoras de grupos de teatro que resistem ao tempo e às duras dificuldades de sustentação do trabalho artístico qualificado na nossa realidade cultural:

- [...] fui convidado a entrar no Grupo [nome] montamos o espetáculo experimental [título da peça] e depois [relata outros espetáculos realizados pelo grupo]. Com esses trabalhos circulamos pelo interior do estado [...] os primeiros contatos com o [cita um grupo reconhecido nacionalmente] e com [cita um importante nome do teatro mundial] transformaram nossa pedagogia de pesquisa, evoluímos imensamente em poucos anos. Além de apresentações surgem as primeiras oficinas ministradas pelo grupo e em grupo. Fator muito importante de reflexão conjunta. Fim dos anos 90 e o grupo acaba, surge o Grupo

Vera Lúcia Bertoni dos Santos, Contadores de Histórias sobre Teatro e Educação

R.bras.est.pres., Porto Alegre, v.1, n.1, p. 189-213, jan./jun., 2011. 
Teatral [nome do atual grupo a que se vincula], herdando toda a estrada percorrida pelos demais [Pedro].

- Com o tempo, eu e a minha grande partner [atriz e diretora de teatro] começamos a almejar coisas maiores, então começamos a convidar outras pessoas mais experientes na área, queríamos algo mais estudado, trabalhado, mais aprimorado. Convidamos o [nome de um profissional da área] para dirigir [...], o [outro profissional] para compor a trilha sonora, o [mais um] para criar os figurinos, a [e outra] para pensar no cenário. E ainda ganhamos um patrocínio da Prefeitura, que milagre! [Bela].

- [Referindo-se a uma das primeira oficinas que frequentou] Dessa oficina nasceram meus primeiros laços profissionais. O convívio com o grupo [nome] rendeu-me experiências em cena, muitos estudos sobre Stanislavski e filósofos como Nietzsche, e a batalha da produção, quando viajamos para [cita o destino da viagem] [Bia].

Outro aspecto fundador da interação dos sujeitos com os conteúdos das disciplinas é a experiência docente. Dessa forma são relatados diversos tipos de atividades, dentre elas as que se constituem espontaneamente, como a do caso descrito por Luna, as relacionadas a oportunidades de ministrar oficinas e cursos informais de teatro ou de dança, referidas por Pedro e Bia, e as localizadas no ambiente escolar em cumprimento a estágios de formação em nível de Magistério ou de integralização curricular à formação acadêmica universitária, refletidas, respectivamente, por Raquel e Lúcia:

- Acompanhei o [diretor de teatro] em oficinas ministradas na periferia da cidade [Luna].

- Ministrei muitas oficinas pelo Estado com sapateiros, agricultores, metalúrgicos, oficinas na periferia e no centro. As mais marcantes foram as com crianças [...] realizei um ano de oficina num projeto cultural ligado à prática teatral [Pedro].

- Depois de monitorar minha professora de dança, montei uma escola com uma colega [...] ministrávamos aulas para alunos de 03 a 40 anos [Bia]. 
- [...] enquanto cursava o magistério [...] realizei o estágio com uma turma de segunda série e muitas intervenções de teatro [referindo-se à sua atividade na universidade]. E fui bolsista em Cursos de Extensão Universitária [Raquel].

- Há três anos [...] comecei a dar aulas de Educação Artística numa escola [orientação religiosa]. No começo ainda me sentia um pouco perdida e insegura de inserir o fazer teatral nas aulas, pois este não era muito bem visto pela direção da escola [...]. A turma apresentava sinais claros de curiosidade e até uma certa ansiedade para começar [Lúcia].

Tais experiências mostram-se valiosas na interação dos licenciandos com os princípios da teoria, tanto pelo seu caráter heterogêneo como pelo seu aspecto unificador, vindo a significar a tematização de conceitos fundamentais à compreensão das relações entre o teatro e a educação.

\section{Encontrar-se}

A parte mais atualizada, diga-se assim, dos Memoriais refere-se ao relacionamento dos sujeitos da pesquisa com a própria formação acadêmica de nível superior; ou seja, reflete as suas formas de pensar as relações de continuidade dos seus processos de conhecimento acerca das perspectivas educacionais do teatro, desde o seu ingresso no Curso de Licenciatura e, mais especialmente, da interação interdisciplinar dessas construções, considerando a diversidade de conteúdos inerentes à formação artística e pedagógica do professor de teatro. Os fragmentos de depoimentos a seguir ilustram esses aspectos:

- Em 1999 passei para o Curso de Licenciatura em Teatro [...] o meu interesse foi mais direcionado pela interdisciplinaridade do teatro com outras artes, relacionado com a licenciatura. Sempre procurando me aperfeiçoar e atualizar em trocas e vivências com workshops, oficinas, cursos, palestras... [Luna].

- No Curso, muitos encontros produtivos e generosos entre colegas e professores [cita alguns] na descoberta de vias interpretativas para a atriz, a diretora e a professora [...] falar e ouvir teatro, aproximar-se do público, dos colegas [Bia].

Vera Lúcia Bertoni dos Santos, Contadores de Histórias sobre Teatro e Educação

R.bras.est.pres., Porto Alegre, v.1, n.1, p. 189-213, jan./jun., 2011. 
- Em 1999, eu entrei no Curso de Licencuatira em Teatro, puxa! Outra transformação, a decisão da profissão, o ir fundo em busca da profissionalização. Tudo muito novo, as pessoas, o ambiente, os assuntos, os professores que no início me metiam medo, um mundo em que me questionei, "será que sou capaz". Fui, investi, aprendi, errei [Bela].

- Ano 2000, ingresso na Licenciatura. Aos poucos fui conhecendo os colegas, hoje grandes amigos, já nos engajamos em esquetes no RU [Espaço do Restaurante Universitário explorado pelos alunos na forma de "intervenções", "performances e "instalações" dos estudantes], Saraus nas Catacumbas [outro desses espaços]. Fui bolsista voluntária de um curso de teatro [no âmbito da extensão Universitária]; [depois de mencionar diversas atividades acadêmicas, conclui] Escrevo então este relato e quem sabe o meu Projeto de Graduação [refere-se ao tema do Trabalho de Conclusão de Curso] aparece [Raquel].

Dentre as constatações mais importantes que esses relatos possibilitam, destacam-se as justificativas dos sujeitos para a escolha do curso universitário, que parecem corresponder a interesses genuínos pelo aprofundamento de um conhecimento já em andamento, ou seja, à perspectiva de domínio do fazer teatral na direção de uma progressiva compreensão.

Outro aspecto relevante desses depoimentos são as considerações sobre o caráter cooperativo da aprendizagem do teatro na experiência universitária: os narradores foram unânimes em enumerar colegas e professores do curso, pondo-os lado a lado nas suas buscas e investimentos.

Observe-se, também, a qualidade autoral das concepções de aprendizagem desses sujeitos, revelada pelo modo de como eles se referem às oportunidades de interação experimentadas no ambiente acadêmico, através do engajamento em diversas práticas, dos encontros, das descobertas, das falas, das reflexões, dos questionamentos, dos erros, das trocas e de outras tantas ações relacionadas à construção de conhecimento.

A interação com esses futuros profissionais do ensino do teatro corresponde a diversas jornadas, e correlaciona-se ao desenvolvimento de uma série de atividades ocorridas em continuidade e refletidas nos

Vera Lúcia Bertoni dos Santos, Contadores de Histórias sobre Teatro e Educação

R.bras.est.pres., Porto Alegre, v.1, n.1, p. 189-213, jan./jun., 2011. 
sucessivos modos de significação dos acontecimentos das suas histórias de vida. $\mathrm{O}$ aspecto processual da organização e da compreensão dessas histórias por parte dos sujeitos afere-se pela constatação do teor preponderantemente descritivo das narrativas iniciais e das primeiras versões dos Memoriais, em relação à qualidade predominantemente interpretativa e reflexiva das narrativas desses mesmos sujeitos nas versões finais dos seus Memoriais e nos seus Trabalhos de Conclusão de Curso.

Os fragmentos de Memoriais relativos ao momento presente (período culminante do semestre, correspondente à etapa final, e de avaliação da disciplina de Metodologia do Ensino do Teatro) atestam a capacidade reflexiva desses estudantes acerca do seu processo de interação com o teatro e com a educação.

- Eu penso, depois de tudo, [...] o quanto a minha estrada é comprida. E agora os projetos para este ano, de dar aula, o trabalho com a [cita o nome do espetáculo que participa como atriz], nossas dificuldades, os grandes desafios, a luta por trabalho e reconhecimento. Uma nova perspectiva, um novo olhar para o teatro [Bela].

- Sem certezas e com muitas possibilidades de caminhos e aprendizado, busco um amadurecimento profissional sem ranços. Sinto-me uma eterna aprendiz, pois o trabalho em grupo sempre surpreende. Por isso continuo no teatro [Luna].

- É o último ano na Graduação, a prática de ensino e o Projeto [cita o nome da colega com a qual pretende compartilhar o Trabalho de Conclusão de Curso], que encontro! - Muitos projetos encubados e o sonho de realizálos com meus colegas da Licenciatura e de grupo. A certeza de ir à luta e não ficar dependendo de projetos "dos governos", de fazer um teatro provocativo [Bia].

A qualidade das inferências desses estudantes sobre o próprio fazer teatral, compreendido como pesquisa e reflexão, bem como o caráter organizador dos seus conhecimentos, remetem ao princípio de indissociabilidade da teoria e da prática na experiência interdisciplinar relacionada à busca por um teatro 
desafiador, provocativo e transformador das relações sociais.

Conforme é possível constatar na pesquisa, cada indivíduo se sente provocado, motivado a formalizar suas experiências dentro e fora da sala de aula, a partir das suas possibilidades, interesses e necessidades de reflexão, apropriando-se dos conteúdos das suas ações à sua própria maneira e compartilhando-a no coletivo.

Um depoimento significativo da interação entre os sujeitos da pesquisa e o curso consta nos fragmentos do capítulo introdutório do Trabalho de Conclusão de Curso da aluna Maria. Referindo-se ao seu percurso de elaboração teórica, ela encadeia os conteúdos desenvolvidos no decorrer da sua formação profissional com extrema clareza, revelando uma compreensão (totalidade) da dinâmica (funcionamento) do seu próprio processo de conhecimento:

Ao aprofundar os conhecimentos no teatro aprendemos muito mais do que parece, e ainda mais sobre nós mesmos [...]. Primeiro foi preciso conhecer e vivenciar as disciplinas fundamentais do curso como: Improvisação Teatral, na qual aprendemos a importância de improvisar, lidar com situações, ter raciocínio rápido e, sobretudo, aprendemos a jogar; Expressão Corporal e Expressão Vocal, disciplinas que nos auxiliam a exprimir nossos pensamentos e emoções através do corpo e da voz; e outras que nos introduzem ao universo teatral. Na disciplina [Metodologia do Ensino de Teatro] comecei a construir a minha identidade como professora [...] ficava surpresa, intrigada com o que lia nos livros [cita teorias com as quais se identifica]. A primeira experiência como professora veio [...] em uma oficina teatral oferecida para a comunidade [relata a experiência obtida na disciplina, e conclui] foi aí que percebi que não seria fácil esta estrada. [referindo-se aos Estágios Docentes] Começou uma nova etapa na minha vida acadêmica [...]. Apesar de querer muito aprender e evoluir, tinha muito medo, afinal era algo desconhecido [...]. Foi uma experiência difícil [...] a partir dela eu começaria a construir a minha caminhada [...]. A realidade da sala de aula mostrou-se mais eficaz do que qualquer teoria. Só frente a frente com os desafios é que nos mobilizamos para mudar o que nos incomoda e pensamos alternativas para continuar nossa caminhada. E foi literalmente caminhando e pensando no que fazer para contribuir para o meu crescimento como professora, e também para o crescimento dos meus futuros

Vera Lúcia Bertoni dos Santos, Contadores de Histórias sobre Teatro e Educação

R.bras.est.pres., Porto Alegre, v.1, n.1, p. 189-213, jan./jun., 2011. 
alunos, que escolhi o tema do meu Trabalho de Conclusão de Curso [Maria].

Esse depoimento evidencia a crescente qualidade da interação dessa futura professora de teatro com as diferentes etapas do curso. Observa-se a incidência das tomadas de consciência possibilitadas por esse processo na estruturação das ações desenroladas no passado recente, relativas, portanto, aos objetivos do trabalho que acabara de realizar, e na projeção de um tempo futuro, em que se vê comprometida com a carreira escolhida.

Analisadas sob o enfoque das teorias do conhecimento de Piaget e Paulo Freire, essas concepções acerca da aprendizagem no tempo, no estreitamento das relações interpessoais e na compreensão da teoria e da prática como construções interdependentes e complementares entre si, levam a refletir sobre a crescente "consciência do inacabamento" (Freire, 1996, p. 55) por parte dos sujeitos da pesquisa, que corresponde, por sua vez, ao princípio de "intangibilidade do objeto do conhecimento".

Em que pesem a pluralidade dos fatos (ou seja, os aspectos do conteúdo) das histórias de vida contadas pelos sujeitos da pesquisa, bem como a diferenciação dos artefatos (referentes, por sua vez, aos aspectos formais) que caracterizam as suas narrativas, observa-se que a experiência pedagógica enfocada neste texto vincula-se, fundamentalmente, à progressiva tomada de consciência desses contadores, futuros professores de teatro, em relação às suas próprias compreensões acerca da docência e do teatro. 


\begin{abstract}
Notas
${ }^{1}$ Os fragmentos de depoimentos analisados no texto foram selecionados dentre uma série de escritos (Memoriais e TCCs) e conversas registradas num diário de campo, que integram o material empírico da investigação. Nas transcrições literais (que figuram ao longo do trabalho em itálico, ou destacadas do corpo do texto) opta-se por preservar as identidades dos sujeitos da pesquisa, o que acarreta a omissão de dados pessoais (nomes de pessoas, cidades, ruas, escolas e grupos de teatro) e a adoção de nomes fictícios para identificar os seus autores.
\end{abstract}

\title{
Referências
}

DAMÁSIO, António. O Mistério da Consciência: do corpo e das emoções ao conhecimento de si. São Paulo: Companhia das Letras, 2000.

FREIRE, Paulo. Pedagogia da Autonomia: saberes necessários à prática educativa. São Paulo: Paz e Terra, 1996.

PIAGET, Jean. Problemas de Psicologia Genética. In: Os Pensadores. São Paulo: Abril Cultural, 1983. P. 209-294.

SARAMAGO, José. A História do Cerco de Lisboa. São Paulo: Companhia das Letras, 1989.

Vera Lúcia Bertoni dos Santos é professora Adjunta e pesquisadora do Departamento de Arte Dramática e do Programa de Pós-Graduação em Artes Cênicas da UFRGS. Doutora em Educação pela UFRGS; membro do GESTE - Grupo de Estudos em Teatro e Educação, do Diretório de Grupos de Pesquisa do CNPq.

E-mail: bertonica@gmail.com

Recebido em janeiro de 2011

Aprovado em abril de 2011

Vera Lúcia Bertoni dos Santos, Contadores de Histórias sobre Teatro e Educação

R.bras.est.pres., Porto Alegre, v.1, n.1, p. 189-213, jan./jun., 2011.

Disponível em http://www.seer.ufrgs.br/presenca 